\title{
Recombinant family 3 carbohydrate-binding module as a new additive for enhanced enzymatic saccharification of whole slurry from autohydrolyzed Eucalyptus globulus wood
}

\author{
Carla Oliveira $(\mathbb{D} \cdot$ Aloia Romaní • Daniel Gomes · Joana T. Cunha • \\ Francisco M. Gama $\cdot$ Lucília Domingues
}

Received: 2 August 2017 / Accepted: 22 February 2018/Published online: 28 February 2018

(C) Springer Science+Business Media B.V., part of Springer Nature 2018

\begin{abstract}
By-products resulting from lignocellulosics pretreatment affect the digestibility of resulting whole slurries, but this can be minimized by additives supplementation. In this work, a family 3 carbohydrate-binding module (CBM3), recombinantly produced from Escherichia coli, was used as additive in the enzymatic hydrolysis of the whole slurry from autohydrolyzed Eucalyptus globulus wood (EGW). At the higher dosage used ( $30 \mathrm{mg} / \mathrm{g}_{\text {solids }}$ ), CBM3 led to an increase in glucose yield from 75 to $89 \%$. A similar result was obtained for bovine serum albumin (BSA) (11\% increase), which has a well-documented additive effect. CBM3 had no effect on the non-productive binding of enzymes, since it could not bind to EGW lignin, while it rapidly bound to cellulose, as shown by fluorescence microscopy. CBM3 is a valid additive for enhanced lignocellulosic saccharification and a valuable alternative to costly additives (e.g. polyethylene glycol) as it can be affordably produced from heterologous bacterium, thus contributing to more costefficient biomass valorization bioprocesses.
\end{abstract}

Keywords Recombinant CBM3 - Whole slurry · Enzyme inhibition · Lignin $\cdot$ Enhanced saccharification

C. Oliveira $(\bowtie) \cdot$ A. Romaní · D. Gomes .

J. T. Cunha · F. M. Gama · L. Domingues

CEB - Centre of Biological Engineering, University of

Minho, Campus de Gualtar, 4710-057 Braga, Portugal

e-mail: carlaoliveira@deb.uminho.pt

\section{Introduction}

Lignocellulosic biomass is the most abundant, lowcost, bio-renewable resource (Capolupo and Faraco 2016). It has a recognised potential as a sustainable platform for the production of biofuels and other biochemicals that can be utilized as building blocks for obtaining new materials (Arevalo-Gallegos et al. 2017). Bioconversion of lignocellulose into glucose is carried out by hydrolytic enzymes (enzymatic saccharification). In order to improve the accessibility of the cellulose component from the complex lignocellulosic structures to the enzymes, a pretreatment step is mandatory. Nevertheless, affinity of cellulases to lignin residues and other inhibitory compounds (phenolic, soluble sugars, furan aldehydes and weak acids) derived from pretreatment, via irreversible binding or precipitation (Ko et al. 2015), hinder the free movement of enzymes necessary for an efficient saccharification (Mhlongo et al. 2015).

The integration of lignocellulosic materials into biorefinery processes in a circular economy is currently hampered by the high cost of enzymes (Gomes et al. 2015). The development of methods that can increase efficiency and decrease bioconversion costs of lignocellulosic biomass is therefore crucial. The use of synergistic proteins (accessory or helper proteins) that can synergistically cooperate with, or protect, cellulases is an emerging strategy for enhanced saccharification of lignocellulosic biomass, resulting in cost reduction with respect to cellulase usage and 
the enzymatic saccharification of lignocellulose (Kim et al. 2014). Notably, protein supplementation might save cellulase loadings by at least $50 \%$ without decreasing hydrolysis yield (Wang et al. 2015). Nonhydrolytic proteins, such as bovine serum albumin (BSA), expansins and expansin-like proteins, engineered peptides, peptone, yeast extract, and carbohydrate-binding modules (CBMs), have been tested in cellulosic or lignocellulosic saccharification with significant positive effects (Kim et al. 2014; Liu et al. 2016). Proteins can act as lignin-blocking additives and/or cellulose amorphogenesis promoters (i.e. non-hydrolytic "opening up" or disruption of cellulose), among other functions (e.g. enzyme protection from thermal deactivation) (Wang et al. 2015), depending on the protein itself and substrate nature. CBMs are small components of most enzymes whose consensual primary role is to anchor the catalytic module to the insoluble substrate (Oliveira et al. 2015a), while a putative secondary role on assisting cellulose depolymerisation is occasionally attributed (Arantes and Saddler 2010). Common uses of CBMs include modification of fibers, production, purification and immobilization of recombinant proteins, functionalization of biomaterials and development of microarrays and probes (Oliveira et al. 2015a). Additionally, some works have shown the capacity of family I CBMs from fungi to improve the enzymatic hydrolysis of cellulose (e.g. Hall et al. 2011; Mello and Polikarpov 2014). However, these proof-of-concept studies have used model substrates, namely filter paper, Avicel and fibrous cellulose, whereas the synergistic potential of CBMs on the saccharification of lignocellulosic materials has not yet been studied. The synergistic potential of the proteins must be evaluated in real substrates to access their robustness to withstand very demanding reaction conditions, which are normally unfavourable to proteins, such as prolonged exposure to high temperatures along with the presence of various inhibitors in pretreated lignocellulosic biomass. CBM3 from Clostridium thermocellum has been widely used in the production and purification of recombinant proteins and peptides (Ramos et al. 2013; Wan et al. 2011), functionalization of biomaterials (Andrade et al. 2010), enhancement of paper strength-related properties (Oliveira et al. 2015b), and interaction studies with cellulose (Gao et al. 2014; Machado et al. 2009); however, it has never been used to improve cellulose or lignocellulose hydrolysis. Therefore, this work aims at investigating the effect of CBMs on the enzymatic hydrolysis of the whole slurry from a hydrothermally-pretreated (autohydrolysis) lignocellulosic biomass-Eucalyptus globulus wood (EGW), an abundant fast-growing hardwood of Iberian Peninsula - using CBM3, recombinantly produced and purified from Escherichia coli, which constitutes a novel application for CBMs.

\section{Materials and methods}

Autohydrolysis pretreatment of Eucalyptus globulus wood (EGW)

Eucalyptus globulus wood (EGW) was mixed with water at Liquid to Solid Ratio (LSR) of $8 \mathrm{~g}$ of water/g of oven-dry raw material in a stainless steel pressurized reactor at $210{ }^{\circ} \mathrm{C}$ in non-isothermal regime. This condition was selected on the basis of previous work (Romaní et al. 2010) in which 51 and $28 \%$ of polysaccharides (mainly cellulose and xylan) were recovered in solid and liquid phases, respectively. After pretreatment, the slurry (unwashed autohydrolyzed EGW solid; EGWs) and liquid phase (autohydrolysis liquor; EGWl) were separated by filtration. Composition of raw material, solid and liquid phases was previously reported in Romaní et al. 2014.

\section{Enzymes}

Enzymatic hydrolysis assays were carried out using the commercial preparation Cellic CTec2 (Novozymes A/S, Denmark), consisting of a composition of enzymes comprising cellulases and $\beta$-glucosidases. The determined enzymatic activity of Cellic CTec2 was 120 filter paper units per millilitre (FPU/mL). The enzymatic activity of Cel7A in commercial preparation was $3786 \mathrm{IU} / \mathrm{mL}$. For lignin isolation, a combination of the commercial cocktail Celluclast and Novozym 188 (both from Novozymes A/S, Denmark) was employed. The activities of these preparations were determined to be $60 \mathrm{FPU} / \mathrm{mL}$ and $611 \mathrm{IU} / \mathrm{mL}$, respectively. Enzymatic activities were determined using standard methods, as described in Rodrigues et al. (2015). 
Proteins

The fusion protein GFP-CBM3 and standard grade BSA was purchased from NZYTech. The previously constructed expressing strain E. coli BL21 (DE3)/ pET21a + CBM3 (Machado et al. 2009) harbouring the CBM3 from the $C$. thermocellum scaffolding protein (CipA) was used for the production of recombinant CBM3. CBM3 was produced and purified according to the conditions reported in Andrade et al. (2010). After purification, protein buffer was exchanged with $0.05 \mathrm{~N}$ citric acid-sodium citrate buffer pH 4.85 using PD10 columns (GE Healthcare). Purified CBM3 was analyzed by SDS-PAGE using $15 \%$ (w/v) acrylamide gel, followed by Coomassie Brilliant Blue staining. The concentration of the recombinant CBM3 was estimated from the absorbance at $280 \mathrm{~nm}$ using its molar extinction coefficient. Recombinant CBM3 was maintained at $4{ }^{\circ} \mathrm{C}$ prior to use.

Enzymatic saccharification of EGW slurry and whole slurry

Enzymatic saccharification assays of whole slurry from autohydrolyzed EGW (EGW whole slurry) were carried out using $0.5 \mathrm{~g}$ of EGWs as substrate in $10 \mathrm{~g}$ of total liquid (containing $73 \%$ of EGWl) at $50{ }^{\circ} \mathrm{C}$ and $\mathrm{pH} 4.85$ (using $0.05 \mathrm{~N}$ citric acid-sodium citrate buffer) in an orbital incubator (150 rpm). Cellulase to substrate loading of $15 \mathrm{FPU} / \mathrm{g}$ was used in all experiments. CBM3 was added to enzymatic experiment at different ratios: 30,15 and $1.5 \mathrm{mg}$ of CBM3 per $g$ of unwashed EGW [corresponding to CBM3/ Cellulase loading of 1:5, 1:10 and 1:100 (w/w)]. BSA was also evaluated using the same loads as CBM3. Experiment without CBM3 or BSA was carried out as control. An additional enzymatic saccharification experiment using EGWs without addition of EGWl was performed in order to determine maximal enzymatic saccharification without inhibitory effect of liquor on cellulolytic enzymes. Enzymatic saccharification assays were carried out in duplicate. Samples were withdrawn at desired times $(24,48,72$ and $113 \mathrm{~h}$ ) and analysed by HPLC for glucose using Refractive Index detector and BioRad Aminex HPX$87 \mathrm{H}$ column, eluted with $0.05 \mathrm{M} \mathrm{H}_{2} \mathrm{SO}_{4}$ at $60{ }^{\circ} \mathrm{C}$ and flow of $0.6 \mathrm{~mL} / \mathrm{min}$. Glucose yields $\left(\mathrm{Y}_{\mathrm{G}}, \%\right)$ of enzymatic saccharifications were calculated as follows:

$\mathrm{Y}_{\mathrm{G}}=\mathrm{G} t / \mathrm{G}_{M A X} \times 100$

In the Eq. (1), Gt represent the glucose concentration at time $t$ in the experiments performed with EGWl and $\mathrm{G}_{M A X}$ the maximal concentration of glucose obtained in the experiments performed without EGWl.

Lignin isolation from autohydrolyzed EGW solid

EGWs was extensively hydrolyzed for $140 \mathrm{~h}$ with a mixture of Celluclast and Novozym 188 in a 1:5 activity ratio and a dosage of $80 \mathrm{FPU} / \mathrm{g}_{\text {cellulose }}$, being carefully washed and freeze-dried afterwards. A $2 \%$ $(\mathrm{w} / \mathrm{v})$ suspension was then prepared in $50 \mathrm{mM}$ Tris$\mathrm{HCl} \mathrm{pH} 7$ buffer and further incubated with $4 \%$ (v/v) alcalase for $24 \mathrm{~h}$. After washed and alkaline treated ( $\mathrm{pH} 10$ ) for $2 \mathrm{~h}, \mathrm{pH}$ was reduced to 2 and the suspension was let to settle overnight $\left(5^{\circ} \mathrm{C}\right)$ to allow precipitation of dissolved lignin. The upper phase (clear liquid on the top) was carefully removed, remaining liquid was filtrated and the solid resuspended in the same volume of $0.05 \mathrm{~N}$ citric acidsodium citrate buffer $\mathrm{pH} 4.85$, and stored until further tests.

CBM3 adsorption experiments

Samples were collected from well-mixed suspensions at specific time points of enzymatic hydrolysis. Liquid and solids were analysed by SDS-PAGE for the presence of free and adsorbed protein, respectively. For that, after sampling, the liquid and solid fractions were separated by centrifugation. Solids were resuspended in the initial volume with citrate buffer. Then, both fractions were boiled for $10 \mathrm{~min}$ with $1 \times$ SDSPAGE sample loading buffer (NZYTech) and applied into the gels.

For the fluorescence experiments, the fusion protein GFP-CBM3 (at the intermediate ratio, $15 \mathrm{mg} / \mathrm{g}_{\text {solids }}$ ) was incubated with EGWs, EGW lignin or Avicel (microcrystalline cellulose), under conditions mimicking enzymatic hydrolysis but in the absence of enzyme. Solids were collected after 2 and $24 \mathrm{~h}$ of incubation and observed under a fluorescence microscope Olympus BX51. Images were acquired with a colour camera Olympus DP72, using the Cell^B software (Olympus). 


\section{Results and discussion}

Enzymatic hydrolysis of EGW whole slurry

The nature of both, hydrolysate (liquor from pretreatment) and pretreated lignocellulosic biomass strongly affect the digestibility of pretreated whole slurries (Yan et al. 2014). Enzymatic saccharification of whole slurry from pretreated lignocellulose is highly desirable as it avoids the solid-liquid separation step, the need for detoxification and related waste disposal problem, thus leading to lower capital and operating costs, and increases final sugar concentration (Romaní et al. 2014). Nevertheless, enzymatic efficiency is significantly reduced by the presence of soluble inhibitory compounds. The inhibitory effect of EGW whole slurry on enzymatic hydrolysis is shown in Fig. 1a, where the time course of glucose production from EGW slurries (with and without EGWl) is represented.

As may be seen in Fig. 1a, a 25\% lower glucose production was obtained in the presence of inhibitory compounds. On the other hand, complete conversion of xylooligosaccharides into xylose was observed in the whole slurry experiments, in the presence or absence of CBM3 (data not shown). Previously identified compounds in EGWl comprise acetic acid, hydroxymethylfurfural (HMF), furfural and phenolic compounds (Romaní et al. 2014). Recently, significant reduction of cellulose hydrolysis was also reported using high purity cellulose mixed with water soluble fraction from steam pretreated poplar containing soluble sugars and inhibitory compounds (Zhai et al. 2015). Various strategies have been developed to avoid or minimize the effects of the inhibitors generated during hydrothermal pretreatment and to thereby enhance the bioconversion of lignocellulose, including supplementation of hydrolysis with noncatalytic proteins (Ko et al. 2015). The potential synergistic effect of CBMs on the enzymatic hydrolysis of pretreated biomass was herein evaluated for the first time.

Impact of CBM3 dosages on enzymatic hydrolysis of EGW whole slurry

CBM3 from C. thermocellum CipA is a well-known CBM with a cellulose-binding function and tridimensional structure far elucidated. In $C$. thermocellum
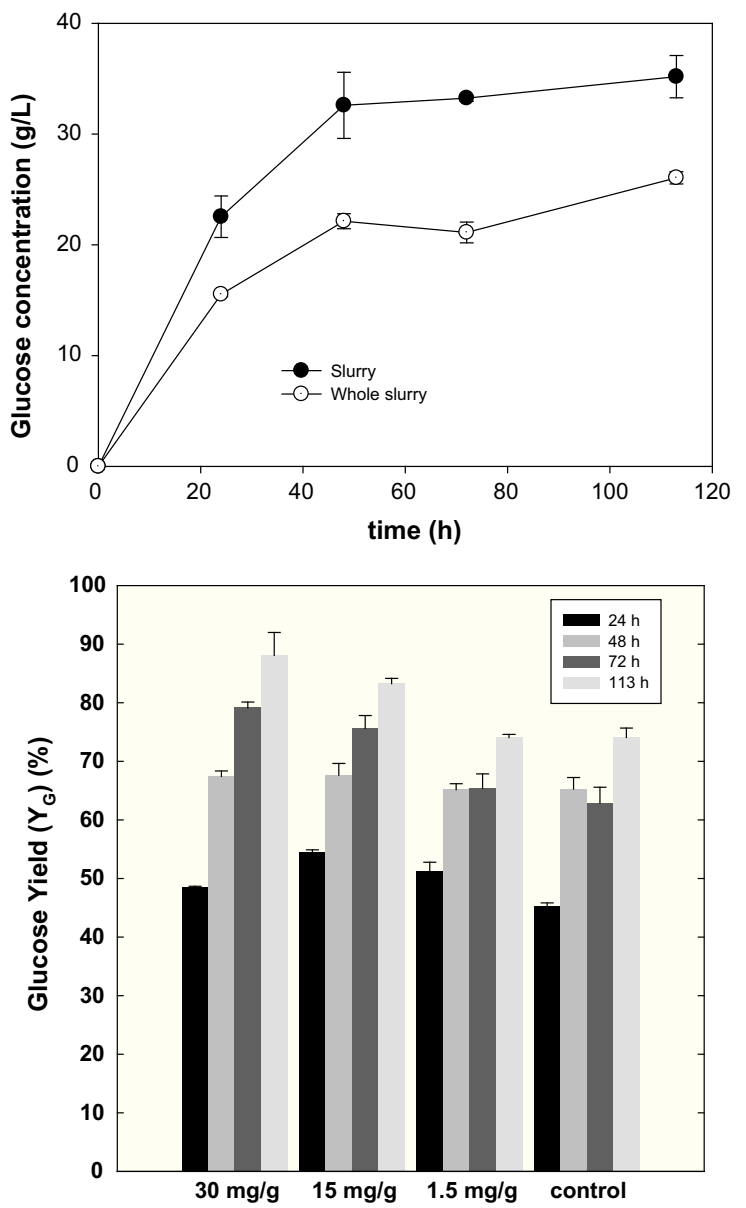

Fig. 1 Time course enzymatic hydrolysis of whole slurry from autohydrolyzed E. globulus wood. Data represent the average \pm standard deviations of two independent experiments. a Influence of autohydrolysis liquor (EGWl) on glucose production $(\mathrm{g} / \mathrm{L})$. b Impact of different dosages of CBM3 (mg protein/g solids) on glucose yield $\left(\mathrm{Y}_{\mathrm{G}}, \%\right)$. Control refers to the assays without addition of CBM3

cellulosome (cell surface-bound protein complex), CBM3 plays a major role in the mediation of cell binding to cellulose (Bayer et al. 1983, 2008; Lamed et al. 1987). The structure of CBM3 consists of nine $\beta$ strands which form a compact domain that has an overall prismatic shape (Tormo et al. 1996). It is arranged in two antiparallel $\beta$-sheets that stack faceto-face to form a $\beta$ sandwich with jelly roll topology. Two defined surfaces, containing conserved polar and aromatic residues, are located on opposite sides of the molecule. The surface forming a planar strip was proposed to interact with crystalline cellulose (Tormo et al. 1996). Although being a widely studied CBM, 


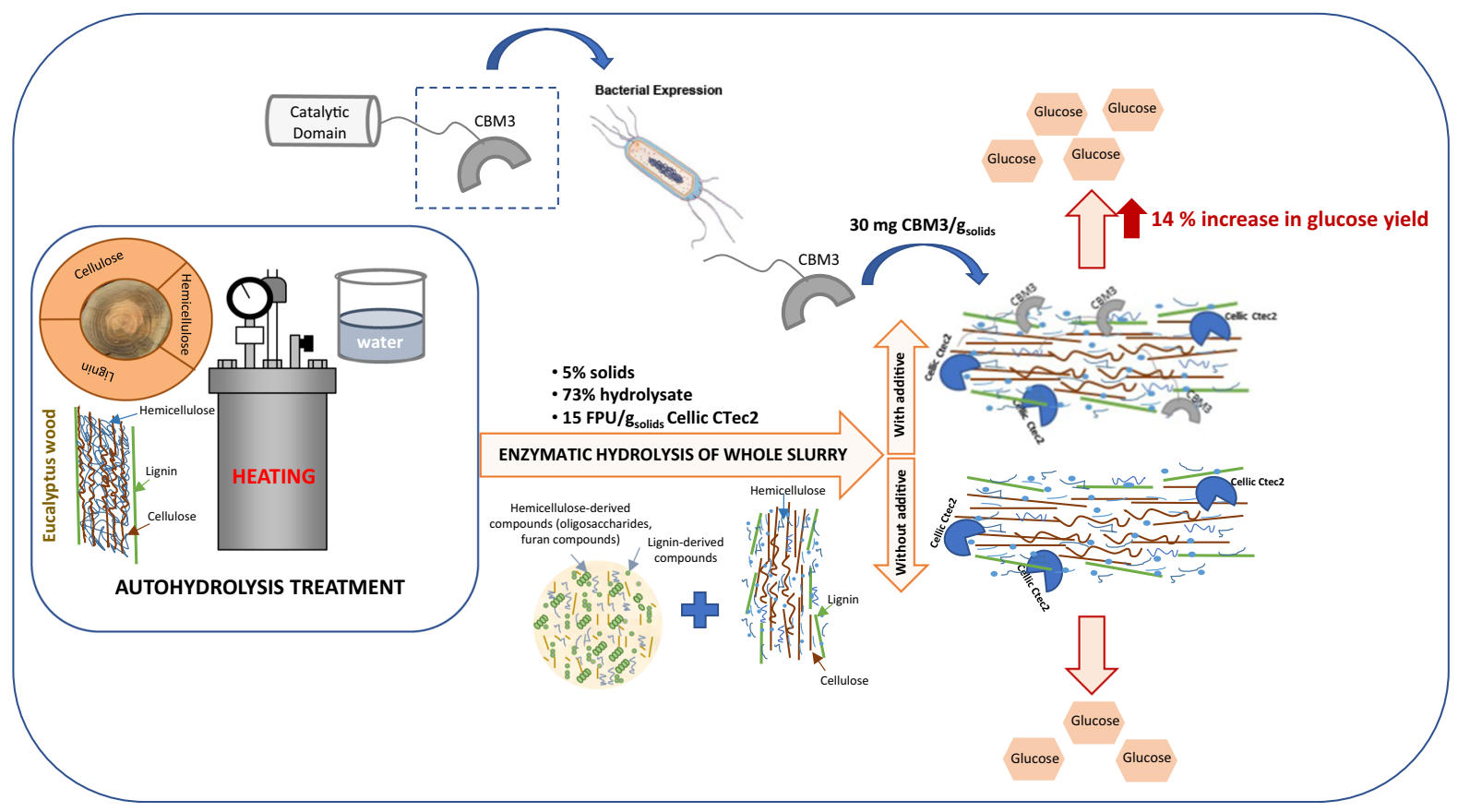

Fig. 2 Schematic representation of the additive effect of CBM3 on the enzymatic saccharification of whole slurry from autohydrolyzed E. globulus wood

the putative additive effect of CBM3 on cellulose/ lignocellulose degradation remains to be demonstrated.

In order to test the effectiveness of CBM3 as protein additive in lignocellulose saccharification, different dosages of this protein $(30-1.5 \mathrm{mg} / \mathrm{g}$ ) were incubated simultaneously with a commercial enzymatic cocktail (Cellic CTec2) in autohydrolyzed EGW; the glucose yield of enzymatic saccharification was determined over time (Fig. 1b). Enzymatic hydrolysis assays were carried out using the whole slurry to evaluate the capacity of CBM3 to compensate the inhibitory effect of EGWl (Fig. 1a). As it can be seen in Fig. 1b, in the control experiments (no CBM3 added), the glucose yield reached only up to $75 \%$. In addition, the lowest CBM3 dosage used $(1.5 \mathrm{mg} / \mathrm{g})$ had no effect on enzymatic hydrolysis, as compared to the control (Fig. 1b). However, the higher CBM3 dosages used (30 and $15 \mathrm{mg} / \mathrm{g}$ ) had a significant positive effect at the end of the hydrolysis (113 h), with glucose yields above $75 \%$ (Fig. 1b). Moreover, glucose yield was near $90 \%$ by the addition of $30 \mathrm{mg}$ CBM3 per $\mathrm{g}$ of solids, which corresponds to a $14 \%$ increase in the hydrolysis efficacy comparing to control. Thus, at this loading, CBM3 is an effective additive for the enzymatic saccharification of EGW whole slurry to be used as proposed in Fig. 2, as it allows overcoming the inhibitory effect of EGWl to a great extent. Results also show that the effect is dose-dependent, with the effective dosage being within the reported range for other proteins (e.g. BSA, 10-50 mg/g) (Yang and Wyman 2006; Wang et al. 2015).

\section{Comparison of BSA and CBM3 synergistic effects}

BSA is one of the most studied synergistic proteins. It is mainly used as a model non-enzymatic protein for comparison with other additives, showing a pronounced positive effect towards the enhancement of enzymatic hydrolysis of different lignocellulosic materials (e.g. Yang and Wyman 2006; Wang et al. 2015). Nevertheless, studies on BSA effects are practically limited to solids (washed or unwashed) from pretreated lignocellulosic biomass; its effects on whole slurries have been scarcely investigated. Moreover, in most works, BSA is incubated prior to the enzymatic hydrolysis to "block" lignin from interacting with cellulase (the most reported BSA mechanism), while the addition of the protein together with the hydrolytic enzymes is a more attractive strategy 
from an integrated point of view. Thus, the effect of the simultaneous addition of BSA in the enzymatic hydrolysis of EGW whole slurry was also studied and the results obtained were compared with those obtained with CBM3, for the highest protein dosage tested (30 mg/g $\mathrm{g}_{\text {solids }}$ ). In this work, BSA led to about $86 \%$ of glucose yield (data not shown), corresponding to $11 \%$ improvement in relation to control. This result is in line with that reported in the literature for BSA effects on the enzymatic hydrolysis of other lignocellulosic materials. For instance, BSA treatment $\left(10-50 \mathrm{mg} / \mathrm{g}_{\text {solids }}\right)$ could enhance the enzymatic hydrolysis of acid-pretreated corn stover and alkaline-pretreated rice straw $(2 \% \mathrm{w} / \mathrm{v})$ by about 10 and $13 \%$ (at $72 \mathrm{~h}$ of hydrolysis), respectively, using the same enzyme loading as used in this work (15 FPU/ $\mathrm{g}_{\text {solids }}$ ) (Yang and Wyman 2006; Wang et al. 2015). Moreover, enzymatic glucose yield of whole slurry from water pretreated poplar wood could be enhanced by around $10 \%$, using 9.3 FPU of Cellic CTec2 (and HTec2) per gram of glucan plus xylan and $1 \%(w / w)$ BSA (Yan et al. 2014). Nevertheless, the glucose yields achieved (73\%) were lower than the ones obtained in this work.

Even though CBM3 and BSA may have different synergistic mechanisms, the two proteins yielded very close glucose concentrations during hydrolysis (Table 1), leading to similar glucose yield increments at the end of the reaction (14 and 11\%, respectively). Moreover, the gain in glucose concentration (up to 25.89\%; Table 1) during hydrolysis when CBM3 was added to the reaction is close to that reported for the effect of family I CBMs on cellulose saccharification, namely up to $25 \%$ (Hall et al. 2011) and $30 \%$ of glucose concentration increase (Mello and Polikarpov 2014), even though in those studies different hydrolysis conditions of pure cellulose models were conducted, which therefore do not contain enzyme inhibitors.

Recombinant CBM3 has potential advantages in cost and availability, as it can be easily and costeffectively produced from E. coli in large amounts, possibly with no need for purification for this application. Furthermore, CBM3 supplementation might save cellulase loadings without decreasing hydrolysis yield, but reducing considerably process costs, since CBM3 production from E. coli is certainly cheaper than cellulolytic enzymes production from fungi or recombinant eukaryotic hosts, as bacteria is the least expensive recombinant protein production platform (Demain and Vaishnav 2009). Moreover, CBM3 has the advantage, over other additives, of being efficiently secreted by yeast (Oliveira et al. 2015b), and thus, robust Saccharomyces cerevisiae strains secreting CBM3 may be developed in a future work for enhanced simultaneous saccharification and fermentation.

\section{CBM3 adsorption on autohydrolyzed EGW}

The liquid fraction from the enzymatic hydrolysis assays was analysed over time by SDS-PAGE for the presence of CBM3. It was observed that CBM3, as well as a large fraction of the Cellic CTec 2 enzymes, were not present in this fraction (Fig. 3a, b). Furthermore, the amount of free enzymes was apparently constant during hydrolysis.

The activity of the most predominant enzyme in the Cellic CTec2 mixture, the exoglucanase Cel7A, was determined in the final supernatants. At this point the free Cel7A was practically zero (IU/mL); only about $2-3 \%$ of Cel7A activity of the initial load is present

Table 1 Effects of CBM3 and BSA addition on glucose production during the enzymatic hydrolysis of whole slurry from autohydrolyzed E. globulus wood for the protein dosage of $30 \mathrm{mg} / \mathrm{g}_{\text {solids }}$

\begin{tabular}{|c|c|c|c|c|c|}
\hline \multirow[t]{2}{*}{ Time of enzymatic hydrolysis (h) } & \multirow{2}{*}{$\begin{array}{l}\text { Control } \\
\text { Glucose (g/ } \\
\text { L) }\end{array}$} & \multicolumn{2}{|l|}{ CBM3 } & \multicolumn{2}{|l|}{ BSA } \\
\hline & & $\begin{array}{l}\text { Glucose (g/ } \\
\mathrm{L})\end{array}$ & $\begin{array}{l}\text { Increase of glucose } \\
\text { concentration }(\%)\end{array}$ & $\begin{array}{l}\text { Glucose }(\mathrm{g} / \\
\mathrm{L})\end{array}$ & $\begin{array}{l}\text { Increase of glucose } \\
\text { concentration }(\%)\end{array}$ \\
\hline 24 & $15.67 \pm 0.20$ & $16.80 \pm 0.06$ & 7.19 & $18.35 \pm 1.73$ & 17.10 \\
\hline 48 & $22.61 \pm 0.68$ & $23.35 \pm 0.33$ & 3.27 & $24.93 \pm 1.17$ & 10.26 \\
\hline 72 & $21.78 \pm 0.94$ & $27.42 \pm 0.33$ & 25.89 & $26.38 \pm 0.65$ & 21.13 \\
\hline 113 & $25.66 \pm 0.55$ & $30.52 \pm 1.36$ & 18.90 & $29.58 \pm 1.40$ & 15.24 \\
\hline
\end{tabular}

Glucose increase (\%) was calculated in relation to the control (no protein added) for the same time point. The values for glucose (g/L) represent the average \pm standard deviations of two independent experiments 
(a)

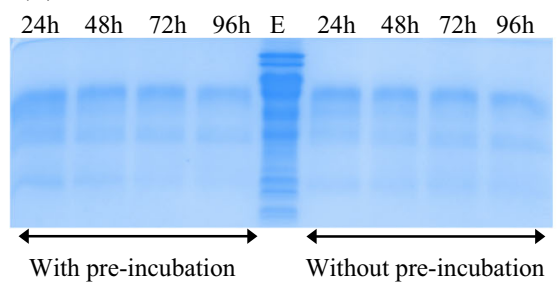

Fig. 3 SDS-PAGE analyses of free protein during the enzymatic hydrolysis of whole slurry from autohydrolyzed $E$. globulus wood in the absence $\mathbf{a}$ and presence $\mathbf{b}$ of CBM3 $(22 \mathrm{kDa})$. Identical results were observed for the three CBM3:Cellic CTec2 ratios studied, the ratio $1: 10(\mathrm{w} / \mathrm{w})$ is

(Table 2), regardless of the conditions tested, even after complete hydrolysis. It may be concluded that Cel7A remained bound to the final residue, which is mainly lignin.

Rodrigues et al. (2015) have also reported that Cel7A from Cellic CTec2 (10 FPU/g g solids $_{\text {) remained }}$ bound to the final residue (lignin), after complete hydrolysis of steam-pretreated wheat straw $(12 \% \mathrm{w} / \mathrm{v}$; $39.03 \%$ Klason lignin), since only about $6 \%$ of active enzyme was found in the final supernatant, being $67 \%$ of the enzyme further recovered from solids. Since free CBM3 could not be found in the liquid fraction of hydrolysis (Fig. 3b), its binding to EGWs was analysed in the first hours of incubation (in absence of Cellic CTec2). After 2 and $5 \mathrm{~h}$ of incubation, the CBM3 was mostly or completely in the solid fraction, respectively (Fig. 4a). However, after $24 \mathrm{~h}$ of incubation, the CBM3 was not detected by SDS-PAGE either in the liquid or in the solid fraction (Fig. 4a).

Fluorescence microscopy with GFP-CBM3 showed that after 2 or $24 \mathrm{~h}$ incubation the CBM3 was indeed in EGWs (Fig. 4b, c). Presumably, protein-cellulose interaction is so strong that CBM3 could not be eluted off from EGWs in SDS-PAGE. This result agrees with data from previous studies, indicating that the (b)

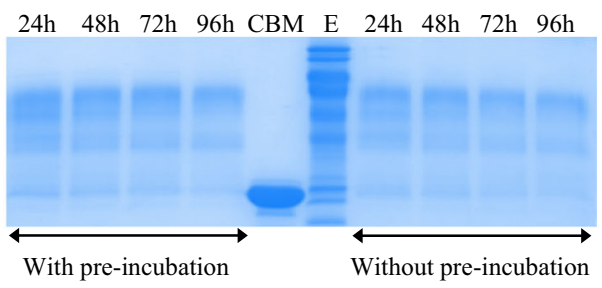

presented. CBM and E correspond to CBM3 and Cellic CTec2, respectively, at the beginning of the hydrolysis. Pre-incubation refers to a pretreatment step with citrate buffer $\mathbf{a}$ or CBM3 $\mathbf{b}$ for $15 \mathrm{~h}$ at $50{ }^{\circ} \mathrm{C}$ prior to enzyme addition

adsorption of CBM3 on cellulose is very stable (Machado et al. 2009). It could also be observed by fluorescence that the binding of CBM3 to autohydrolyzed EGW fibers was not homogeneous, but occurred in regions characterized by disordered packing (non-uniformity), like the extremities, as reported in previous work for the binding of CBM3 to EGW fibers from ECF bleached kraft pulp (Oliveira et al. 2015b). This is consistent with the first step of the theoretical amorphogenesis mechanism of CBMs on cellulose, which involves their adsorption at cellulose defects, such as micro-cracks (Arantes and Saddler 2010).

Structurally modified lignin and/or small ligninderived molecules in liquor together with the residual lignin in solids can inhibit cellulase during whole slurry hydrolysis through the so-called non-productive binding (Liu et al. 2016). Moreover, it has been shown that lignins obtained from pretreated woods (eucalyptus, maple or pine) adsorb 2-6 times more cellulase than lignins obtained from untreated woods (Liu et al. 2016). In this study, previous or simultaneous addition of CBM3 did not seem to affect the binding of Cellic CTec2 enzymes to EGWs, since the amount of free enzymes is almost the same in the presence and

Table 2 Activity of Cel7A in the liquid fraction at the end of the enzymatic hydrolysis of whole slurry from autohydrolyzed $E$. globulus in the presence of CBM3 at the dosages of 15 and $30 \mathrm{mg} / \mathrm{g}_{\text {solids }}$

\begin{tabular}{lll}
\hline CBM3 dosage $(\mathrm{mg}$ protein/g & solids & Remaining activity of Cel7A (\%) \\
\hline 0 (control) & Activity of free Cel7A (IU/mL) & $1.67 \pm 0.02$ \\
15 & $0.390 \pm 0.004$ & $2.12 \pm 0.01$ \\
30 & $0.496 \pm 0.002$ & $2.75 \pm 0.06$ \\
\hline
\end{tabular}

Control refers to the experiments without addition of CBM3. Remaining activity (\%) was calculated by the reason between the measured and the initial $(23.38 \mathrm{UI} / \mathrm{mL})$ enzymatic activities. The values represent the average \pm standard deviations of two independent enzymatic assays 
(a)

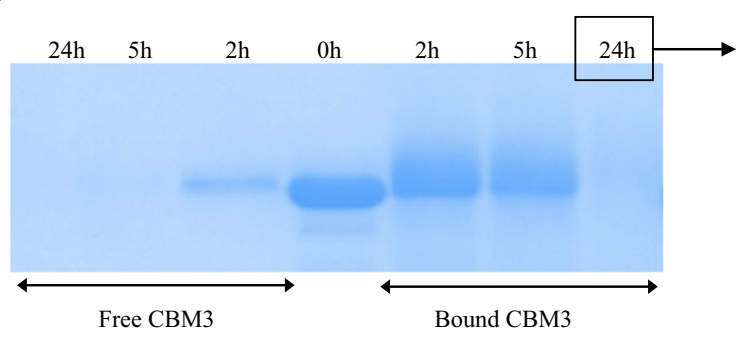

(c)

(d)
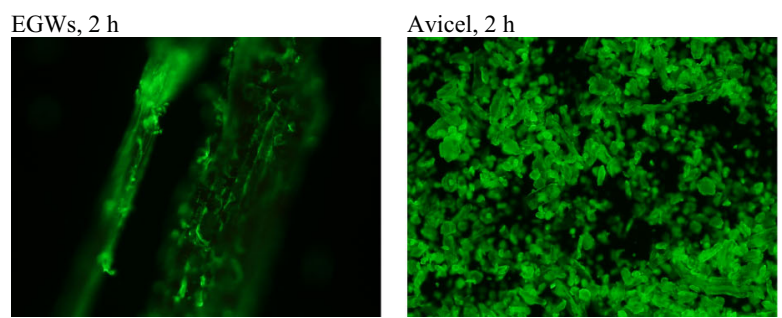

(b)

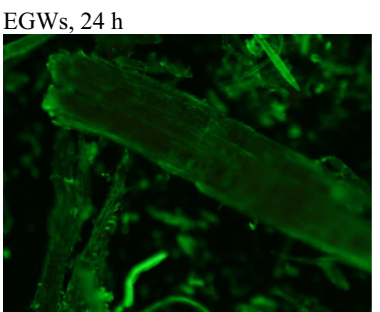

(e)

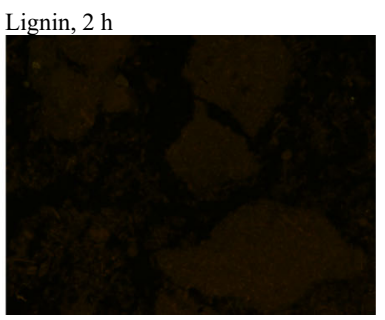

Fig. 4 Adsorption of CBM3 (22 kDa) on autohydrolyzed $E$. globulus solids (EGWs) at $50{ }^{\circ} \mathrm{C}$ studied by SDS-PAGE (a) and fluorescence microscopy $(\mathbf{b}, \mathbf{c})$. Fluorescence microscopy is also shown for the binding assay of CBM3 with Avicel (d),

absence of CBM3, as judged by SDS-PAGE (Fig. 3a, b) and analysis of free Cel7A activity (Table 2), while it significantly enhanced hydrolysis. Putative mechanisms responsible for the observed additive effects could include improved substrate surface area (Pinto et al. 2004), reduced substrate crystallinity (Hall et al. 2011), titration of non-productive enzyme binding sites (Gao et al. 2014), in particular to the crystalline regions of cellulose, where CBM3 adsorbs with higher affinity. This work confirms the additive effect played by different proteins, since both CBM3 and BSA, used in similar dosages, induce a similar effect on the degradation rate. Thus, this effect seems to be rather unspecific, not relying on a particularly higher cellulose-adsorption affinity. Furthermore, CBM3 could not block lignin from putative non-productive binding of enzymes, since it did not bind to this EGW component (Fig. 4e). CBM3 most probably acts synergistically with cellulase on cellulose, by reducing the recalcitrance of the substrate, as claimed by other authors for family I CBMs (e.g. Mello and Polikarpov 2014), which results in better hydrolysis, as also suggest data from literature when $\mathrm{CBM} 3$ is fused to cellulase. For example, when $C$. thermocellum CBM3 was fused to the Cel7A from Talaromyces emersonii performed as positive control, and for the binding assay of CBM3 with the lignin isolated from EGWs (e), which revealed no fluorescence either at 2 or $24 \mathrm{~h}$

(TeCel7A), the resulting enzyme (Te Cel7A-CBM3) was more efficient in the hydrolysis of Avicel compared to TeCel7A-CBM1 (CBM1 from Trichoderma reesei Cel7A), TeCel7A wild type, and Cel7A from $T$. reese $i$, at all studied temperatures (Voutilainen et al. 2014). However, in the presence of lignin, the hydrolysis degree of Avicel (mixed in equal parts) was lower for TeCel7A-CBM3 than for TeCel7A-CBM1 at higher temperatures $\left(55\right.$ and $65^{\circ} \mathrm{C}$ ), due to a stronger binding of $\mathrm{TeCel7A}-\mathrm{CBM} 3$ to lignin (Rahikainen et al. 2013). However, as shown in this work, lignin is not a challenge for CBM3 action. The binding of cellulase to lignin is governed by non-covalent forces, which strongly depends on both the enzyme characteristics (i.e., cellulose-binding modules, key amino acid residues, and net surface charge) and the physicochemical properties of lignin (i.e., hydrophobicity, charged groups, phenolic hydroxyl groups, and molecular weight) (Liu et al. 2016). Among them, hydrophobic interactions are the major cause of nonproductive binding of cellulase to lignin, which are mainly mediated by intrinsic CBMs (e.g. family I $\mathrm{CBMs}$ ). Thus, enzyme engineering for lignocellulose hydrolysis must be carefully addressed considering the complexity of pretreated biomasses, reaction 
conditions, and the possible modification of structure and properties of both, the enzyme and fused CBMs, in chimeric enzymes. In fact, intrinsic CBMs were shown unessential for enzymatic hydrolysis of pretreated lignocellulosics at high consistencies, being their absence favourable for enzyme recycling (Várnai et al. 2014). However, enzymatic yields are particularly low under these highly demanding hydrolysis conditions. Accordingly, addition of CBMs separately from the enzymes is a promising alternative for efficient process intensification.

\section{Conclusions}

The impact of CBM3 on the enzymatic hydrolysis of the whole slurry from autohydrolyzed E. globulus wood was studied for the first time. The negative effect of inhibitory compounds on EGW whole slurry saccharification was compensated by the simultaneous addition of recombinant CBM3 at the dosage of $30 \mathrm{mg} / \mathrm{g}_{\text {solids }}$ ( $14 \%$ increase in glucose yield). This effect was not related to the blocking of lignin from enzyme binding. BSA at the same loading as CBM3 showed a similar result (11\% increase in glucose yield). CBM3 is a new additive that may be included in enzymatic cocktails for enhanced whole slurry saccharification.

Acknowledgments This work was developed under the strategic funding of UID/BIO/04469/2013 unit, COMPETE 2020 (POCI-01-0145-FEDER-006684) and BioTecNorte operation (NORTE-01-0145-FEDER-000004) funded by the European Regional Development Fund under the scope of Norte2020-Programa Operacional Regional do Norte. The research leading to the reported results has received funding from Fundação para a Ciência e a Tecnologia (FCT) through the project MultiBiorefinery (POCI-01-0145-FEDER-016403) and through grants to C. Oliveira (SFRH/BPD/110640/2015) and D. Gomes (SFRH/BD/88623/2012).

\section{Compliance with ethical standards}

Conflict of interest The authors declare that they have no conflict of interest.

\section{References}

Andrade FK, Costa R, Domingues L, Soares R, Gama M (2010) Improving bacterial cellulose for blood vessel replacement: functionalization with a chimeric protein containing a cellulose-binding module and an adhesion peptide. Acta Biomater 6:4034-4041

Arantes V, Saddler JN (2010) Access to cellulose limits the efficiency of enzymatic hydrolysis: the role of amorphogenesis. Biotechnol Biofuels 3:4

Arevalo-Gallegos A, Ahmad Z, Asgher M, Parra-Saldivar R, Iqbal HM (2017) Lignocellulose: a sustainable material to produce value-added products with a zero waste approachA review. Int J Biol Macromol 99:308-318

Bayer EA, Kenig R, Lamed R (1983) Adherence of Clostridium thermocellum to cellulose. J Bacteriol 156:818-827

Bayer EA, Lamed R, White BA, Flint HJ (2008) From cellulosomes to cellulosomics. Chem Rec 8:364-377

Capolupo L, Faraco V (2016) Green methods of lignocellulose pretreatment for biorefinery development. Appl Microbiol Biotechnol 100:9451-9467

Demain AL, Vaishnav P (2009) Production of recombinant proteins by microbes and higher organisms. Biotechnol Adv 27:297-306

Gao SH, You C, Renneckar S, Bao J, Zhang YHP (2014) New insights into enzymatic hydrolysis of heterogeneous cellulose by using carbohydrate-binding module 3 containing GFP and carbohydrate-binding module 17 containing CFP. Biotechnol Biofuels 7:24

Gomes D, Rodrigues AC, Domingues L, Gama M (2015) Cellulase recycling in biorefineries-Is it possible? Appl Microbiol Biotechnol 99:4131-4143

Hall M, Bansal P, Lee JH, Realff MJ, Bommarius AS (2011) Biological pretreatment of cellulose: enhancing enzymatic hydrolysis rate using cellulose-binding domains from cellulases. Bioresour Technol 102:2910-2915

Kim IJ, Lee HJ, Choi IG, Kim KH (2014) Synergistic proteins for the enhanced enzymatic hydrolysis of cellulose by cellulase. Appl Microbiol Biotechnol 98:8469-8480

Ko JK, Um Y, Park Y-C, Seo J-H, Kim K-H (2015) Compounds inhibiting the bioconversion of hydrothermally pretreated lignocelllulose. Appl Microbiol Biotechnol 99:4201-4212

Lamed R, Naimark J, Morgenstern E, Bayer EA (1987) Specialized cell surface structures in cellulolytic bacteria. J Bacteriol 169:3792-3800

Liu H, Sun JL, Leu SY, Chen SC (2016) Toward a fundamental understanding of cellulase-lignin interactions in the whole slurry enzymatic saccharification process. Biofuels Bioprod Biorefining 10:648-663

Machado J, Araújo A, Pinto R, Gama FM (2009) Studies on the interaction of the carbohydrate binding module 3 from the Clostridium thermocellum CipA scaffolding protein with cellulose and paper fibres. Cellulose 16:817-824

Mello BL, Polikarpov I (2014) Family 1 carbohydrate bindingmodules enhance saccharification rates. AMB Express $4: 36$

Mhlongo SI, den Haan R, Viljoen-Bloom M, van Zyl WH (2015) Lignocellulosic hydrolysate inhibitors selectively inhibit/deactivate cellulose performance. Enzyme Microb Technol 81:16-22

Oliveira C, Carvalho V, Domingues L, Gama FM (2015a) Recombinant CBM-fusion technology-applications overview. Biotechnol Adv 33:358-369

Oliveira C, Sepúlveda G, Aguiar TQ, Gama FM, Domingues L (2015b) Modification of paper properties using carbohydrate-binding module 3 from the Clostridium 
thermocellum CipA scaffolding protein produced in Pichia pastoris: elucidation of the glycosylation effect. Cellulose 22:2755-2765

Pinto R, Moreira S, Mota M, Gama M (2004) Studies on the cellulose-binding domains adsorption to cellulose. Langmuir 20:1409-1413

Rahikainen JL, Moilanen U, Nurmi-Rantala S, Lappas A, Koivula A, Viikari L, Kruus K (2013) Effect of temperature on lignin-derived inhibition studied with three structurally different cellobiohydrolases. Bioresour Technol 146:118-125

Ramos R, Moreira S, Rodrigues A, Gama M, Domingues L (2013) Recombinant expression and purification of the antimicrobial peptide magainin-2. Biotechnol Prog 29:17-22

Rodrigues AC, Haven MO, Lindedam J, Felby C, Gama M (2015) Celluclast and Cellic(R) CTec2: saccharification/ fermentation of wheat straw, solid-liquid partition and potential of enzyme recycling by alkaline washing. Enzyme Microb Technol 79-80:70-77

Romaní A, Garrote G, Alonso JL, Parajó JC (2010) Bioethanol production from hydrothermally pretreated Eucalyptus globulus wood. Bioresour Technol 101:8706-8712

Romaní A, Ruiz HA, Pereira FB, Domingues L, Teixeira JA (2014) Effect of hemicellulose liquid phase on the enzymatic hydrolysis of autohydrolyzed Eucalyptus globulus wood. Biomass Conv Bioref 4:77-86

Tormo J, Lamed R, Chirino AJ, Morag E, Bayer EA, Shoham Y et al (1996) Crystal structure of a bacterial family-III cellulose-binding domain: a general mechanism for attachment to cellulose. EMBO J 15:5739-5751

Várnai A, Makela MR, Djajadi DT, Rahikainen J, Hatakka A, Viikari L (2014) Carbohydrate-binding modules of fungal cellulases: occurrence in nature, function, and relevance in industrial biomass conversion. Adv Appl Microbiol 88:103-165

Voutilainen SP, Nurmi-Rantala S, Penttilä M, Koivula A (2014) Engineering chimeric thermostable GH7 cellobiohydrolases in Saccharomyces cerevisiae. Appl Microbiol Biotechnol 98:2991-3001

Wan W, Wang D, Gao X, Hong J (2011) Expression of family 3 cellulose-binding module (CBM3) as an affinity tag for recombinant proteins in yeast. Appl Microbiol Biotechnol 91:789-798

Wang H, Kobayashi S, Mochidzuki K (2015) Effect of nonenzymatic proteins on enzymatic hydrolysis and simultaneous saccharification and fermentation of different lignocellulosic materials. Bioresour Technol 190:373-380

Yan L, Zhang L, Yang B (2014) Enhancement of total sugar and lignin yields through dissolution of poplar wood by hot water and dilute acid flowthrough pretreatment. Biotechnol Biofuels 7:76

Yang B, Wyman CE (2006) BSA treatment to enhance enzymatic hydrolysis of cellulose in lignin containing substrates. Biotechnol Bioeng 94:611-617

Zhai R, Hu J, Saddler JN (2015) What are the major components in steam pretreated lignocellulosic biomass that inhibit the efficcacy of cellulase enzyme mixtures? ACS Sustain Chem Eng 4:3429-3436 